\title{
An Overview of the Recent European Federation of Neurological Societies Guidelines on the Treatment of Tension-type Headache
}

\author{
Lars Bendtsen
}

Senior Consultant, Danish Headache Centre, Department of Neurology, Glostrup Hospital, University of Copenhagen

\begin{abstract}
Tension-type headache (TTH) is the most prevalent headache type and causes a high degree of disability. This paper provides an overview of the recently published European Federation of Neurological Societies guideline on the treatment of TTH, which recommended that non-drug management should always be considered for this condition. For example: information, reassurance and identification of trigger factors may be rewarding; electromyograph biofeedback has a documented effect in $\mathrm{TH}$; cognitive-behavioural therapy and relaxation training most likely also are effective; and physical therapy and acupuncture may be valuable options for patients with frequent TTH. Simple analgesics and non-steroidal anti-inflammatory drugs are recommended for treatment of episodic TTH. Combination analgesics containing caffeine are drugs of second choice. Excessive use of analgesics should be avoided to prevent the development of medication-overuse headache. The tricyclic antidepressant amitriptyline is the first choice for prophylactic treatment of chronic TTH. Mirtazapine and venlafaxine may be used second line.
\end{abstract}

\section{Keywords}

Guideline, tension-type headache, management, prophylaxis, antidepressants

Disclosure: In 2010, Lars Bendtsen received honoraria from Merck Sharp and Dohme, Pfizer and Berlin-Chemie.

Received: 12 October 2010 Accepted: 4 January 2011 Citation: European Neurological Review, 2011;6(1):64-9 DOl:10.17925/ENR.2011.06.01.64

Correspondence: Lars Bendtsen, Danish Headache Centre, Glostrup Hospital, University of Copenhagen, DK-2600 Glostrup, Denmark. E: Iarben01@glo.regionh.dk

This paper gives an overview of the recent guideline on the treatment of tension-type headache (TTH) published by a task force of the European Federation of Neurological Societies (EFNS). ${ }^{1}$ The guideline aimed to give evidence-based recommendations for the acute and prophylactic drug treatment of TTH. In addition, it aimed to provide a short overview of non-drug treatments for TTH based on the best performed controlled trials, reviews and meta-analyses.

TTH is classified into three subtypes according to frequency: infrequent episodic TTH, frequent episodic TTH and chronic $\mathrm{TTH}^{2}$ (see Table 1). This division may seem artificial but it has proved to be highly relevant for several reasons. First, impact on quality of life differs considerably between the subtypes. A person experiencing headache every day from the time of waking, persisting until bedtime, month in and month out, is disabled. At the other extreme, a mild headache once every other month has very little impact on health or functional ability and needs little if any medical attention. Second, the pathophysiological mechanisms may differ significantly between the subtypes; peripheral mechanisms are probably more important in episodic TTH, whereas central pain mechanisms are pivotal in chronic $\mathrm{TTH}^{3}{ }^{3}$ Third, treatment differs between the subtypes, with symptomatic and prophylactic treatments being more appropriate for episodic and chronic TTH, respectively. It is essential, therefore, to make a precise diagnosis, which is assisted by completion of a headache diary, ${ }^{4}$ kept for at least four weeks.

The recommendations in the guideline were based on scientific evidence from clinical trials and were agreed by consensus among the expert members of a task force of the EFNS. They considered randomised placebo-controlled trials and trials comparing different treatments for drug treatments. For non-drug treatments controlled trials were considered. The definitions of the recommendation levels followed the EFNS criteria. ${ }^{5}$ Briefly, a level A rating (established as effective, ineffective or harmful) requires at least one convincing class I study or at least two consistent, convincing class || studies. A level B rating (probably effective, ineffective or harmful) requires at least one convincing class II study or overwhelming class III evidence. A level C rating (possibly effective, ineffective or harmful) requires at least two convincing class III studies. ${ }^{5}$

\section{Epidemiology, Clinical Aspects and Diagnosis}

Population based studies have demonstrated that TTH is highly prevalent: $24-37 \%$ of the adult population have TTH several times a month; $10 \%$ have TTH weekly; and 2-3\% have chronic TTH, usually lasting for the greater part of a lifetime. ${ }^{6,7} \mathrm{~A}$ recent review of the global prevalence and burden of headaches showed that the societal burden resulting from disability caused by TTH (and hence its overall cost) is greater than that of migraine. ${ }^{8}$

TTH is characterized by a bilateral, pressing, tightening pain of mild-to-moderate intensity, occurring either in short episodes of variable duration (episodic forms) or continuously (chronic form). The headache is not associated with typical features of migraine, such as vomiting, severe photophobia and phonophobia. Chronic TTH may be associated with either photophobia, phonophobia or mild nausea (see Table 1). ${ }^{2}$ The lack of accompanying symptoms and the relatively 
mild pain means that patients are rarely severely incapacitated by pain. TTH is the most featureless of the primary headaches and, since many secondary headaches may mimic TTH, a diagnosis of TTH requires exclusion of other organic disorders.

The diagnosis of TTH is based on the patient's history and a normal neurological examination. The diagnosis should be confirmed by means of a headache diary. ${ }^{4}$ The most difficult differential diagnosis is between TTH and mild migraine. The diary may also reveal triggers and medication overuse. It also will establish the baseline against which to measure the efficacy of treatments. Identification of a high intake of analgesics is essential because medication overuse requires specific treatment.9 Paraclinical investigations, in particular brain imaging, are necessary if secondary headache is suspected (e.g. the headache characteristics are atypical); if the course of headache attacks changes; or if persistent neurological or psychopathological abnormalities are present. Significant co-morbidity - e.g. anxiety or depression - should be identified and treated concomitantly. It should be explained to the patient that frequent TTH is only seldomly cured, but that meaningful improvements often can be obtained using combinations of drug and non-drug treatments.

\section{Acute Drug Treatment of Tension-type Headache}

Acute drug therapy refers to the treatment of individual attacks of headache in patients with episodic and chronic TTH. Most headaches in patients with episodic TTH are mild to moderate and the patients often can self-medicate with simple (non-opiate) analgesics (paracetamol or aspirin) or non-steroidal anti-inflammatory drugs (NSAIDs). The efficacy of simple analgesics tends to decrease with increasing frequency of the headaches. In patients with chronic TTH, the headaches are often associated with stress, anxiety and depression. simple analgesics are usually ineffective and should be used with caution because of the risk of medication-overuse headache $(\mathrm{MOH})$ when they are used regularly for more than 14 days a month. $\mathrm{MOH}$ is also a risk when triptans or combination analgesics are used for more than nine days a month. ${ }^{10}$ Other interventions, such as non-drug treatments and prophylactic pharmacotherapy, should be considered.

\section{Simple Analgesics and Non-steroidal Anti-inflammatory Drugs \\ Paracetamol 1,000mg was significantly more effective than placebo in most, ${ }^{11-17}$ but not all, ${ }^{18,19}$ trials; three trials found no significant effect for paracetamol 500-650mg compared with placebo. ${ }^{11,18,20}$ Aspirin has consistently been reported to be more effective than placebo at

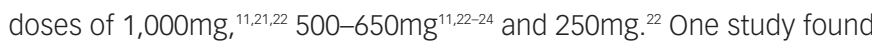 no difference in efficacy between solid and effervescent aspirin. ${ }^{24}$}

Doses of ibuprofen at $800 \mathrm{mg}^{23}{ }^{23} 400 \mathrm{mg}^{14,15,23,25,26}$ and $200 \mathrm{mg}^{27}$ are more effective than placebo, as are ketoprofen 50mg, ${ }^{18,27} 25 \mathrm{mg}^{17,19,27}$ and $12.5 \mathrm{mg} .{ }^{19}$ Diclofenac $25 \mathrm{mg}$ and $12.5 \mathrm{mg}$ have been reported to be effective. ${ }^{25}$ There are no TTH trials of the higher doses of 50-100mg proved effective in migraine. Naproxen $375 \mathrm{mg}^{16}$ and $550 \mathrm{mg}^{20,28}$ also have been shown to be effective.

\section{Optimal Dosing}

One study demonstrated a significant dose-response relationship for aspirin, with 1,000mg being superior to 500mg and 500mg being superior to $250 \mathrm{mg} .{ }^{22}$ Ketoprofen $25 \mathrm{mg}$ tends to be more effective than
Table 1: Diagnostic Criteria for Tension-type Headache (International Headache Society Classification) ${ }^{2}$

\subsection{Infrequent Episodic Tension-type Headache}

A. At least 10 episodes occurring on $<1$ day per month on average $(<12$ days per year) and fulfilling criteria $B-D$

B. Headache lasting from 30 minutes to 7 days

C. Headache has at least two of the following characteristics:

1. bilateral location

2. pressing/tightening (non-pulsating) quality

3. mild or moderate pain intensity

4. not aggravated by routine physical activity such as walking or climbing stairs

D. Both of the following:

1. no nausea or vomiting (anorexia may occur)

2. no more than one of photophobia or phonophobia

E. Not attributed to another disorder

2.2 Frequent Episodic Tension-type Headache

\section{As 2.1 except for:}

A. At least 10 episodes occurring on $\geq 1$ but $<15$ days per month for at least 3 months ( 212 and $<180$ days per year) and fulfilling criteria B-D

\subsection{Chronic Tension-type Headache}

\section{As 2.1 except for:}

A. Headache occurring on $\geq 15$ days per month on average for $>3$ months

( $\geq 180$ days per year) and fulfilling criteria B-D

B. Headache lasts hours or may be continuous

D. Both of the following:

1. no more than one of photophobia, phonophobia or mild nausea

2. neither moderate or severe nausea or vomiting

\section{Table 2: Recommended Drugs for Acute Therapy of} Tension-type Headache

\begin{tabular}{|c|c|c|c|}
\hline Substance & Dose & $\begin{array}{l}\text { Level of } \\
\text { Recommendation }\end{array}$ & Comment \\
\hline Ibuprofen & 200-800mg & $A$ & $\begin{array}{l}\text { Gastrointestinal side } \\
\text { effects, risk of bleeding }\end{array}$ \\
\hline Ketoprofen & $25 \mathrm{mg}$ & A & $\begin{array}{l}\text { Side effects as for } \\
\text { ibuprofen }\end{array}$ \\
\hline Aspirin & 500-1,000mg & A & $\begin{array}{l}\text { Side effects as for } \\
\text { ibuprofen }\end{array}$ \\
\hline Naproxen & 375-550mg & A & $\begin{array}{l}\text { Side effects as for } \\
\text { ibuprofen }\end{array}$ \\
\hline Diclofenac & 12.5-100mg & A & $\begin{array}{l}\text { Side effects as for } \\
\text { ibuprofen, only doses of } \\
\text { 12.5-25mg tested in TTH }\end{array}$ \\
\hline Paracetamol & 1,000mg (oral) & A & $\begin{array}{l}\text { Lower risk of } \\
\text { gastrointestinal side } \\
\text { effects than seen } \\
\text { with NSAIDS }\end{array}$ \\
\hline \multicolumn{2}{|c|}{ Caffeine comb. 65-200mg } & B & See below* \\
\hline
\end{tabular}

The level of recommendation considers side effects and consistency of the studies. There is sparse evidence for optimum doses. The most effective dose that is well tolerated by the patient should be chosen. *Combination with caffeine 65-200 mg increases the efficacy of ibuprofen ${ }^{32}$ and paracetamol, ${ }^{13,31}$ but may also increase the risk of developing medication-overuse headache..$^{35,40}$ Level of recommendation of combination drugs containing caffeine is therefore $B$. NSAID = non-steroidal anti-inflammatory drug; TTH = tension-type headache.

$12.5 \mathrm{mg},{ }^{19}$ while one study found very similar effects of ketoprofen $25 \mathrm{mg}$ and 50mg. ${ }^{27}$ Paracetamol 1,000mg seems to be superior to 500mg, since only the former dose has been shown to be effective. In the absence of any evidence about a drug's efficacy, the most effective dose that is well tolerated by the patient should be chosen. suggested doses are presented in Table 2. 
Table 3: Recommended Drugs for Prophylactic Therapy of Tension-type Headache

\begin{tabular}{lll}
$\begin{array}{l}\text { Substance } \\
\text { Drug of First Choice }\end{array}$ & Daily Dose & $\begin{array}{l}\text { Level of } \\
\text { Recommendation }\end{array}$ \\
\hline Amitriptyline & $30-75 \mathrm{mg}$ & A \\
\hline $\begin{array}{l}\text { Drugs of Second Choice } \\
\text { Mirtazapine }\end{array}$ & B \\
\hline Venlafaxine & $30 \mathrm{mg}$ & B \\
\hline Drugs of Third Choice & $150 \mathrm{mg}$ & \\
\hline Clomipramine & & B \\
\hline Maprotiline & $75-150 \mathrm{mg}$ & B \\
\hline Mianserin & $75 \mathrm{mg}$ & B \\
\hline
\end{tabular}

The level of recommendation considers side effects and number and quality of the studies.

Table 4: Non-pharmacological Treatments for Tension-type Headache

\begin{tabular}{ll} 
Treatment & Level of Recommendation \\
\hline Psycho-behavioural Treatments & \\
Electromyograph biofeedback & A \\
\hline Cognitive-behavioural therapy & C \\
\hline Relaxation training & C \\
\hline Physical Therapy & C \\
Acupuncture & C
\end{tabular}

The level of recommendation considers side effects and number and quality of the studies.

\section{Comparison of Simple Analgesics}

NSAIDs have been reported to be more effective than paracetamol in

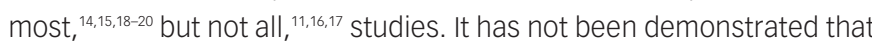
any particular NSAID is superior to any other. ${ }^{21,23,25,27,29}$ NSAIDs have more gastrointestinal side effects than paracetamol, but the use of large amounts of paracetamol may cause liver injury. Among NSAIDS, ibuprofen seems to have the most favourable side-effect profile. ${ }^{30}$

\section{Combination Analgesics}

The efficacy of simple analgesics and NSAIDs is increased by combination with caffeine 64-200mg. ${ }^{12,13,31-34}$ There are no comparative studies examining the efficacy of combinations containing codeine. It is clinically well-known that caffeine withdrawal can cause headache, and chronic daily headache has been reported to be associated with use of over-the-counter caffeine combination products. ${ }^{35}$ It is probable, therefore, that combinations of simple analgesics or NSAIDs with caffeine are more likely to induce $\mathrm{MOH}$ than simple analgesics or NSAIDs alone. Combinations of simple analgesics with codeine or barbiturates should not be used, because the latter increase the risk of developing $\mathrm{MOH}^{35}$

\section{Triptans, Muscle Relaxants and opioids}

Triptans most likely do not have a clinically relevant effect in patients with $\mathrm{TTH}^{36,37}$ neither have muscle relaxants demonstrated efficacy in episodic $\mathrm{TTH}^{38}$ Use of opioids increases the risk of developing $\mathrm{MOH}^{35}$

\section{Conclusions}

Simple analgesics and NSAIDS are the mainstays of acute therapy of TTH (see Table 2). Paracetamol 1,000mg is probably less effective than the NSAIDS, but has a better gastric side-effect profile. ${ }^{39}$ Ibuprofen 400mg may be the drug of choice among the NSAIDs, because of its favourable gastrointestinal side-effect profile compared with other
NSAIDS. ${ }^{39}$ Combination analgesics containing caffeine are more effective than simple analgesics or NSAIDs alone, but are regarded by some experts to be more likely to induce $\mathrm{MOH} .{ }^{40}$ Physicians should be aware of the risk of patients developing $\mathrm{MOH}$ as a result of frequent and excessive use of all types of analgesics in acute therapy. Triptans, muscle relaxants and opioids are not recommended for the treatment of TTH.

\section{Recommendations}

simple analgesics and non-steroidal anti-inflammatory drugs are recommended for treatment of episodic (acute) TTH. Combination analgesics containing caffeine are drugs of second choice. It is crucial to avoid frequent and excessive use of analgesics to prevent the development of medication-overuse headache.

\section{Prophylactic Drug Treatment of Tension-type Headache}

Prophylactic pharmacotherapy should be considered in patients with chronic TTH, and it can be considered in patients with very frequent episodic TTH. Co-morbid disorders, e.g. overweight or depression, should be taken into account

\section{Amitriptyline}

Lance and Curran have reported that amitriptyline 10-25mg three times daily is effective against $\mathrm{TTH}^{.11}$ Diamond and Baltes found amitriptyline $10 \mathrm{mg} /$ day to be effective, but not $60 \mathrm{mg} / \mathrm{day}{ }^{42}$ and amitriptyline $75 \mathrm{mg} /$ day reduced the duration of headache in the final week of a six-week study. ${ }^{43}$ In another study, there was no difference in the size of the effect with amitriptyline $50-75 \mathrm{mg} /$ day, amitriptylinoxide $60-90 \mathrm{mg} /$ day and placebo. ${ }^{44}$ Bendtsen et al. ${ }^{45}$ found that amitriptyline $75 \mathrm{mg}$ daily reduced the area under the headache curve (calculated as headache duration multiplied by headache intensity) by $30 \%$ compared with placebo, which was highly significant. Holroyd et al. ${ }^{46}$ treated patients with antidepressants (83\% took amitriptyline median dose $75 \mathrm{mg} /$ day and $17 \%$ took nortriptyline median dose $50 \mathrm{mg} /$ day) and compared the results with stress management therapy and with a combination of stress management and antidepressant treatment. After six months, all three treatments were approximately 30\% more effective than placebo at reducing the headache index.

Amitriptyline should be started at low dosages (10-25mg/day) and titrated by 10-25mg weekly until the patient either achieves a good therapeutic effect or encounters side effects. It is important that patients are informed that this is an antidepressant agent which has an independent action on pain. The maintenance dose is usually 30-75mg daily administered one to two hours before bedtime to help to circumvent any sedative effects. The effect is not related to the presence of depression. ${ }^{45} \mathrm{~A}$ significant effect with amitriptyline may be observed in the first week of treatment at the therapeutic dose. ${ }^{45}$ If the patient does not respond after four weeks on maintenance dose, it is therefore advisable to switch to other prophylactic therapy. The side effects of amitriptyline include dry mouth, drowsiness, dizziness, obstipation and weight gain.

\section{Other Antidepressants}

The tricyclic antidepressant clomipramine $75-150 \mathrm{mg} /$ day $^{47}$ and the tetracyclic antidepressants maprotiline $75 \mathrm{mg} /$ day $^{48}$ and mianserin $30-60 \mathrm{mg} / \mathrm{day}^{47}$ have been reported to be more effective than placebo. Interestingly, some of the newer more selective antidepressants with action against serotonin and noradrenaline seem to be as effective as 
amitriptyline but have the advantage of being tolerated at the doses required for treatment of a concomitant depression. Thus, the noradrenergic and specific serotonergic antidepressant mirtazapine $30 \mathrm{mg} /$ day reduced the headache index by $34 \%$ more than placebo in difficult-to-treat patients without depression, including patients refactory to amitriptyline. ${ }^{49}$ The efficacy of mirtazapine was found to be comparable to that of amitriptyline. ${ }^{45}$ A systematic review concluded that the two treatments may be equally effective for the treatment of chronic TTH. ${ }^{50}$

The serotonin and noradrenaline reuptake inhibitor venlafaxine $150 \mathrm{mg} / \mathrm{day}^{51}$ reduced headache days from 15 to 12 per month in a mixed group of patients with either frequent episodic or chronic TTH. By contrast, selective serotonin reuptake inhibitors (SSRIS) have not been found to be effective. ${ }^{45,52,53}$ The major side effects of mirtazapine are drowsiness and weight gain, while those of venlafaxine are vomiting, nausea, dizziness and loss of libido.

\section{Miscellaneous Agents}

There have been conflicting results for treatment with the muscle relaxant tizanidine..$^{48,54}$ Botulinum toxin has been extensively studied but a systematic review concluded that it is is likely to be ineffective or harmful for the treatment of chronic TTH. ${ }^{50,55-65}$

\section{Conclusions}

Amitriptyline has a clinically relevant prophylactic effect in patients with chronic TTH and should be the drug of first choice (see Table 3) Mirtazapine or venlafaxine are probably effective, while the older tricyclic and tetracyclic antidepressants clomipramine, maprotiline and mianserin are possibly effective.

\section{Recommendations}

Amitriptyline is the first choice drug for prophylaxis in chronic TTH. Mirtazapine and venlafaxine are second choice drugs and should be considered if amitriptyline is not effective or not tolerated. Discontinuation should be attempted every six to 12 months. The physician should keep in mind that the efficacy of preventive drug therapy in TTH is often modest, and that the benefits of treatment should outweigh the side effects.

\section{Non-pharmacologic Treatment of Tension-type Headache} Information, Reassurance and Identification of Trigger Factors

Non-drug management should be considered for all patients with TTH and is widely used; however, the scientific evidence for efficacy of most treatment modalities is sparse. ${ }^{66-69}$ The very fact that a physician takes the problem seriously may have a therapeutic effect, particularly if the patient is concerned about serious disease (e.g. a brain tumour) and can be reassured by a thorough examination. The physician should attempt to identify triggers, since coping with triggers may be of value. ${ }^{70}$ The most often reported triggers for TTH are stress (mental or physical), irregular or inappropriate meals, high intake or withdrawal of coffee and other caffeine-containing drinks, dehydration, sleep disorders, too much or too little sleep, reduced or inappropriate physical exercise, psycho-behavioural problems and variations during the female menstrual cycle and hormonal substitution. ${ }^{.1-73}$

Information about the nature of the disease is important. It can be explained that muscle pain can lead to a disturbance of the brain's pain-modulating mechanisms, ${ }^{3,74,75}$ so that normally innocuous stimuli are perceived as painful, with secondary perpetuation of muscle pain and risk of anxiety and depression. Long-term prognosis was found to be favourable in a population-based 12-year epidemiological follow-up study, since approximately half of all individuals with frequent or chronic TTH had remission of their headaches. ${ }^{76}$ It is not known whether the same is true for individuals who seek medical consultation.

\section{Psycho-behavioural Treatments Electromyograph Biofeedback}

The aim of EMG biofeedback is to help the patient to recognise and control muscle tension by providing continuous feedback about muscle activity. Sessions typically include an adaptation phase, baseline phase, training phase (where feedback is provided) and a self-control phase, where the patient practices controlling muscle tension without the aid of feedback. ${ }^{77}$ A recent extensive and thorough meta-analysis including 53 studies concluded that biofeedback has a medium-to-large effect. The effect was found to be long-lasting and enhanced by combination with relaxation therapy. ${ }^{78}$ The majority of the studies included employed EMG-biofeedback. It was not possible to draw reliable conclusions as to whether the effect differed between patients with episodic and chronic TTH.

\section{Cognitive Behavioural Therapy}

The aim of cognitive behavioural therapy is to teach the patient to identify thoughts and beliefs that generate stress and aggravate headaches. These thoughts are then challenged, and alternative adaptive coping self-instructions are considered. ${ }^{77}$ One study found cognitive behavioural therapy, or treatment with tricyclic antidepressants or a combination of the two to be better than placebo, with no significant difference between treatments ${ }^{46}$ Another study reported no difference between cognitive behavioural therapy and amitriptyline. ${ }^{79}$ cognitive behavioural therapy may be effective but there is no convincing evidence..$^{50,68}$

\section{Relaxation Training}

The goal of relaxation training is to help the patient to recognise and control tension as it arises in the course of daily activities. Relaxation training involves a range of affective, cognitive and behavioural techniques, such as breathing exercises and meditation. A recent review concluded that there is conflicting evidence that relaxation is better than no treatment, waiting list or placebo. ${ }^{68}$

\section{Non-invasive Physical Therapy}

Physical therapy is widely used for the treatment of TTH and includes the improvement of posture, massage, spinal manipulation, oromandibular treatment, exercise programmes, hot and cold packs, ultrasound and electrical stimulation, but the majority of these modalities have not been properly evaluated. ${ }^{80}$ Active treatment strategies are generally recommended ${ }^{80}$ Exercise, ${ }^{81}$ physiotherapy, ${ }^{82}$ a combination of various techniques such as massage, relaxation and home-based exercises ${ }^{83}$ and craniocervical training ${ }^{84}$ have all been reported to be effective. There is a huge contrast between the widespread use of physical therapies and the lack of robust scientific evidence for supporting their efficacy. ${ }^{67,80,85,86}$

\section{Acupuncture and Nerve Block}

The prophylactic effect of acupuncture has been investigated in several trials in patients with TTH with conflicting results. .0,69,8,2,87-96 $^{-1}$ 
Taken together, the available evidence suggests that acupuncture could be a valuable option for patients who are suffering from frequent $\mathrm{TTH}^{6}{ }^{69}$ but more research is needed before final conclusions can be drawn.

\section{Conclusions}

EMG-biofeedback has an effect in TTH, while cognitive behavioural therapy and relaxation training may have an effect in $\mathrm{TTH}$, but at this moment there is no convincing evidence to support this These treatments are relatively time-consuming, but unfortunately there are no documented guidelines for which psycho-behavioural treatment(s) to choose for the individual patient. Therefore until scientific evidence is provided common sense must be used. It is likely, therefore, that cognitive behavioural therapy will be most beneficial for the patient where psycho-behavioural problems or affective distress play a major role, while biofeedback or relaxation training may be preferable for the tense patient. Physical therapy and acupuncture may be valuable options for patients with frequent TTH, but there is no robust scientific evidence for their efficacy.

\section{Recommendations}

Non-drug management should always be considered, although the scientific basis is limited. EMG biofeedback has a documented effect in TTH, while cognitive behavioural therapy and relaxation training most likely are effective, but there is no convincing evidence. Information, reassurance and identification of trigger factors also may be rewarding. Physical therapy and acupuncture may be valuable options for patients with frequent TTH.
1. Bendtsen $L$, Evers $S$, Linde $M$, et al., EFNS guideline on the treatment of tension-type headache - Report of an EFNS tas force, Eur J Neurol, 2010:17:1318-25.

2. Headache Classification Subcommittee of the International Headache Society, The International Classification of Headache Disorders: 2nd edition, Cephalalgia, 2004;2 (Suppl. 1):1-160.

3. Bendtsen L, Central sensitization in tension-type headache possible pathophysiological mechanisms, Cephalalgia, 2000;20: 486-508.

4. Russell MB, Rasmussen BK, Brennum J, et al., Presentation of a new instrument: the diagnostic headache diary, Cephalalgia, 1992:12:369-74.

5. Brainin M, Barnes M, Baron JC, et al., Guidance for the preparation of neurological management guidelines by EFNS scientific task forces-revised recommendations 2004 Eur J Neurol, 2004;11:577-81.

6. Rasmussen BK, Epidemiology of headache, Cephalalgia, 1995;15:45-68.

7. Lyngberg AC, Rasmussen BK, Jorgensen T, Jensen R, Has the prevalence of migraine and tension-type headache changed over a 12-year period? A Danish population survey, Eur J Epidemiol, 2005:20:243-9.

8. Stovner $L$, Hagen $K$, Jensen $R$, et al., The global burden of headache: a documentation of headache prevalence and disability worldwide, Cephalalgia, 2007;27:193-210.

9. Katsarava Z, Jensen R, Medication-overuse headache: where are we now?, Curr Opin Neurol, 2007;20:326-30

10. Olesen J, Bousser MG, Diener HC, et al., New appendix criteria open for a broader concept of chronic migraine Cephalalgia, 2006;26:742-6.

11. Steiner $\mathrm{TJ}$, Lange $\mathrm{R}$, Voelker $\mathrm{M}$, Aspirin in episodic tension-type headache: placebo-controlled dose-ranging comparison with paracetamol, Cephalalgia, 2003;23:59-66.

12. Schachtel BP, Thoden WR, Konerman JP, et al., Headache pain model for assessing and comparing the efficacy of over-the-counter analgesic agents, Clin Pharmacol Ther, 1991;50:322-9

13. Migliardi JR, Armellino JJ, Friedman M, et al., Caffeine as an analgesic adjuvant in tension headache, Clin Pharmacol Ther, 1994:56:576-86.

14. Schachtel BP, Furey SA, Thoden WR, Nonprescription ibuprofen and acetaminophen in the treatment of tension-type headache, J Clin Pharmacol, 1996:36:1120-5

15. Packman B, Packman E, Doyle G, et al., Solubilized ibuprofen: evaluation of onset, relief, and safety of a novel formulation in the treatment of episodic tension-type headache, Headache, 2000;40:561-7.

16. Prior MJ, Cooper KM, May LG, Bowen DL, Efficacy and safety of acetaminophen and naproxen in the treatment of tension-type headache. A randomized, double-blind placebo-controlled trial, Cephalalgia, 2002;22:740-8.

17. Steiner $\mathrm{TJ}$, Lange $\mathrm{R}$, Ketoprofen $(25 \mathrm{mg}$ ) in the symptomatic treatment of episodic tension-type headache: double-blind placebo-controlled comparison with acetaminophen (1000 mg), Cephalalgia, 1998;18:38-43.

18. Dahlöf CGH, Jacobs LD, Ketoprofen, paracetamol and placebo in the treatment of episodic tension-type headache Cephalalgia, 1996;16:117-23.

19. Mehlisch DR, Weaver M, Fladung B, Ketoprofen, acetaminophen, and placebo in the treatment of tension headache, Headache, 1998:38:579-89.

20. Miller DS, Talbot CA, Simpson W, Korey A, A comparison of naproxen sodium, acetaminophen and placebo in the treatment of muscle contraction headache, Headache 1987;27:392-6.

21. Martinez-Martin P, Raffaelli E Jr, Titus F, et al., Efficacy and safety of metamizol vs. acetylsalicylic acid in patients with moderate episodic tension-type headache: a randomized double-blind, placebo- and active-controlled, multicentre study, Cephalalgia, 2001;21:604-10.

22. Von Graffenried B, Nuesch E, Non-migrainous headache for the evaluation of oral analgesics, $\mathrm{Br}$ I Clin Pharmacol,

1980;10(Suppl. 2):225S-31S.
23. Diamond $S$, Ibuprofen versus aspirin and placebo in the treatment of muscle contraction headache, Headache, 1983:23:206-10.

24. Langemark M, Olesen J, Effervescent ASA versus solid ASA in the treatment of tension headache. A double-blind, placebo controlled study, Headache, 1987;27:90-5.

25. Kubitzek F, Ziegler G, Gold MS, et al., Low-dose diclofenac potassium in the treatment of episodic tension-type headache, Eur J Pain, 2003;7:155-62.

26. Schachtel BP, Thoden WR, Onset of action of ibuprofen in the treatment of muscle-contraction headache, Headache, 1988;28:471-4.

27. van Gerven JM, Schoemaker RC, Jacobs LD, et al, Self-medication of a single headache episode with ketoprofen, ibuprofen or placebo, home-monitored with an electronic patient diary, Br J Clin Pharmacol, 1996;42: $475-81$

28. Pini LA, Del BE, Zanchin G, et al., Tolerability and efficacy of a combination of paracetamol and caffeine in the treatment of tension-type headache: a randomised, double-blind, double-dummy, cross-over study versus placebo and naproxen sodium, J Headache Pain, 2008:9:367-73.

29. Lange $R$, Lentz $R$, Comparison ketoprofen, ibuprofen and naproxen sodium in the treatment of tension-type headache Drugs Exp Clin Res, 1995;21:89-96.

30. Verhagen AP, Damen L, Berger MY, et al., Is any one analgesic superior for episodic tension-type headache?, J Fam Pract, 2006;55:1064-72.

31. Ward N, Whitney C, Avery D, Dunner D, The analgesic effects of caffeine in headache, Pain, 1991:44:151-5.

32. Diamond S, Balm TK, Freitag FG, Ibuprofen plus caffeine in the treatment of tension-type headache, Clin Pharmacol Ther, $2000 \cdot 68: 312-9$

33. Diener $H C$, Pfaffenrath $V$, Pageler L, et al, The fixed combination of acetylsalicylic acid, paracetamol and caffeine is more effective than single substances and dua combination for the treatment of headache: a multicentre, randomized, double-blind, single-dose, placebo-controlled parallel group study, Cephalalgia, 2005;25:776-87.

34. Cerbo R, Centonze V, Grazioli I, et al., Efficacy of a fixed combination of indomethacin, prochlorperazine, and caffein in the treatment of episodic tension-type headache: a double-blind, randomized, nimesulide-controlled, paralle group, multicentre trial, Eur J Neurol, 2005;12:759-67.

35. Scher Al, Lipton RB, Stewart WF, Bigal M, Patterns of medication use by chronic and episodic headache sufferers in the general population: results from the frequent headache epidemiology study, Cephalalgia, 2009; 2010;30:321-8.

36. Brennum J, Brinck T, Schriver L, et al., Sumatriptan has no clinically relevant effect in the treatment of episodic tension-type headache, Eur I Neurol, 1996:3:23-8.

37. Brennum J, Kjeldsen M, Olesen J, The 5-HT1-like agonist sumatriptan has a significant effect in chronic tension-type headache, Cephalalgia, 1992:12:375-9.

38. Mathew N, Ashina M, Acute Pharmacotherapy of Tension-Type Headaches. In: Olesen J, Goadsby PJ, Ramadan N, Tfelt-Hansen P, Welch KM (Eds), The Headaches 3rd edition, Philadelphia: Lippincott Williams Wilkins, 2005;727-33

39. Langman MJ, Weil J, Wainwright P, et al., Risks of bleeding peptic ulcer associated with individual non-steroidal anti-inflammatory drugs, Lancet, 1994:343:1075-8.

40. Bigal ME, Lipton RB, Overuse of acute migraine medications and migraine chronification, Curr Pain Headache Rep. 2009:13:301-7.

41. Lance JW, Curran DA, Treatment of chronic tension headache, Lancet, 1964;1:1236-9.

42. Diamond S, Baltes BJ, Chronic tension headache - treated with amitriptyline - a double-blind study, Headache, 1971:11:110-6

43. Göbel H, Hamouz V, Hansen C, et al., Chronic tension-type headache: amitriptyline reduces clinical headache-duration and experimental pain sensitivity but does not alter pericranial muscle activity readings, Pain, 1994:59:241-9.

44. Pfaffenrath $\mathrm{V}$, Diener $\mathrm{HC}$, Isler $\mathrm{H}$, et al., Efficacy and tolerability of amitriptylinoxide in the treatment of chronic tension-type headache: a multi-centre controlled study, Cephalalgia, 1994;14:149-55

45. Bendtsen L, Jensen R, Olesen J, A non-selective (amitriptyline), but not a selective (citalopram), serotonin reuptake inhibitor is effective in the prophylactic treatment of chronic tension-type headache, I Neurol Neurosurg Psychiatry 1996;61:285-90.

46. Holroyd KA, O'Donnell FJ, Stensland M, et al., Management of chronic tension-type headache with tricyclic antidepressant medication, stress management therapy, and their combination: a randomized controlled trial, I Am Med Assoc, 2001;285:2208-15

47. Langemark M, Loldrup D, Bech P, Olesen J, Clomipramine and mianserin in the treatment of chronic tension headache. A double-blind, controlled study, Headache, 1990;30:118-21.

48. Fogelholm R, Murros K, Tizanidine in chronic tension-type headache: a placebo controlled double-blind cross-over study, Headache, 1992;32:509-13.

49. Bendtsen $L$, Jensen $R$, Mirtazapine is effective in the prophylactic treatment of chronic tension-type headache, Neurology, 2004;62:1706-11

50. Silver N, Headache (chronic tension-type), Clinical Evidence, 2007;1-21.

51. Zissis $\mathrm{N}$, Harmoussi S, Vlaikidis $\mathrm{N}$, et al., A randomized, double-blind, placebo-controlled study of venlafaxine XR in out-patients with tension-type headache, Cephalalgia, 2007;27:315-24.

52. Singh NN, Misra S, Sertraline in chronic tension-type headache, J Assoc Physicians India, 2002;50:873-8.

53. Moja PL, Cusi C, Sterzi RR, Canepari C, Selective serotonin re-uptake inhibitors (SSRIS) for preventing migraine and tension-type headaches, Cochrane Database Syst Rev, 2005; CD002919

54. Murros K, Kataja M, Hedman C, et al., Modified-release formulation of tizanidine in chronic tension-type headache, Headache, 2000;40:633-7.

55. Padberg M, de Bruijn SF, de Haan RJ, Tavy DL, Treatment of chronic tension-type headache with botulinum toxin: a double-blind, placebo-controlled clinical trial, Cephalalgia 2004:24:675-80.

56. Relja M, Telarovic $S$, Botulinum toxin in tension-type headache, I Neurol, 2004;251(Suppl. 1):12-4

57. Rollnik JD, Tanneberger O, Schubert M, et al., Treatment of tension-type headache with botulinum toxin type A: a double-blind, placebo-controlled study, Headache, 2000;40:300-5.

58. Schmitt WJ, Slowey E, Fravi N, et al., Effect of botulinum toxin A injections in the treatment of chronic tension-type headache: a double-blind, placebo-controlled trial, Headache, 2001;41:658-64.

59. Schulte-Mattler W」, Krack P, BoNTTH Study Group, Treatment of chronic tension-type headache with botulinum toxin $A$ : a randomized, double-blind, placebo-controlled multicenter study, Pain, 2004;109:110-4

60. Smuts JA, Baker MK, Smuts HM, Prophylactic treatment of chronic tension-type headache using botulinum toxin type $A$ Eur J Neurol, 1999;(Suppl. 6): S99-S102

61. Göbel H, Lindner V, Krack PK, Treatment of chronic tension-type headache with botulinum toxin, a double blind, placebo-controlled clinical trial, Cephalalgia, 1999;19:455.

62. Silberstein $S D$, Gobel $H$, Jensen $R$, et al.. Botulinum toxin type $A$ in the prophylactic treatment of chronic tension-type headache: a multicentre, double-blind, randomized, placebocontrolled, parallel-group study, Cephalalgia, 2006;26:790-800.

63. Kokoska MS, Glaser DA, Burch CM, Hollenbeak CS, Botulinum toxin injections for the treatment of frontal tension headache, J Headache Pain, 2004;5:103-9.

64. Harden RN, Cottrill J, Gagnon CM, et al., Botulinum toxin a in the treatment of chronic tension-type headache with cervical myofascial trigger points: a randomized, double-blind, placebo-controlled pilot study, Headache, 2009:49:732-43. 
65. Straube A, Empl M, Ceballos-Baumann A, et al., Pericranial injection of botulinum toxin type A (Dysport) for tension-type headache - a multicentre, double-blind, randomized, placebo-controlled study, Eur J Neurol, 2008:15:205-13.

66. Vernon $\mathrm{H}, \mathrm{MCD}$ ermaid $\mathrm{CS}$, Hagino $\mathrm{C}$, Systematic review of randomized clinical trials of complementary/alternative therapies in the treatment of tension-type and cervicogenic headache, complement Ther Med, 1999:7:142-55

67. Bronfort G, Nilsson N, Haas M, et al., Non-invasive physical treatments for chronic/recurrent headache, Cochrane Database Syst Rev, 2004;CD001878.

68. Verhagen AP, Damen L, Berger MY, et al., Behavioral treatments of chronic tension-type headache in adults: are they beneficial?, CNS Neurosci Ther, 2009:15:183-205.

69. Linde $\mathrm{K}$, Allais G, Brinkhaus B, et al., Acupuncture for tension-type headache, Cochrane Database Syst Rev, 2009:CD007587.

70. Martin PR, MacLeod C, Behavioral management of headache triggers: Avoidance of triggers is an inadequate strategy, Clin Psychol Rev, 2009;29:483-95.

71. Nash JM, Thebarge RW, Understanding psychological stress, its biological processes, and impact on primary headache, Headache, 2006;46:1377-86.

72. Ulrich V, Russell MB, Jensen R, Olesen J, A comparison of tension-type headache in migraineurs and in non-migraineurs: a population-based study, Pain, 1996;67: 501-6.

73. Rasmussen $B K$, Jensen $R$, Schroll $M$, Olesen J, Interrelations between migraine and tension-type headache in the general population, Arch Neurol, 1992;49:914-8.

74. Fumal A, Schoenen J, Tension-type headache: current research and clinical management, Lancet Neurol, 2008; 70-83.

75. Bendtsen L, Jensen R, Tension-type headache, Neurol Clin, 2009;27:525-35.
76. Lyngberg AC, Rasmussen BK, Jorgensen $T_{\text {, Jensen }} \mathrm{R}_{\text {, }}$ Prognosis of migraine and tension-type headache: population-based follow-up study, Neurology, 2005;65:580-5.

77. Holroyd KA, Martin PR, Nash JM, Psychological treatments of tension-type headache In: Olesen J, Goadsby PJ, Ramadan N et al. (eds), The Headaches. 3 d ed

78. Nestoriuc $Y$, Rief $W$, Martin A, Meta-analysis of biofeedback for tension-type headache: efficacy, specificity, and treatment moderators, I Consult Clin Psychol 2008;76:379-96.

79. Holroyd KA, Nash JM, Pingel JD, et al., A comparison of pharmacological (amitriptyline $\mathrm{HCL}$ ) and nonpharmacological (cognitive-behavioral) therapies for chronic tension headaches, I Consult Clin Psychol, 1991;59:387-93.

80. Jensen R, Roth JM, Physiotherapy of tension-type headaches. In: Olesen J, Goadsby PJ, Ramadan N, et al. (eds), The Headaches. 3rd Edition, Philadelphia: Lippincott Williams Wilkins, 2005:721-6.

81. Fricton J, Velly A, Ouyang W, Look JO, Does exercise therapy improve headache? a systematic review with meta-analysis, Curr Pain Headache Rep, 2009;13:413-9.

82. Carlsson J, Fahlcrantz A, Augustinsson LE, Muscle tenderness in tension headache treated with acupuncture or physiotherapy, Cephalalgia, 1990;10:131-41.

83. Torelli P, Jensen R, Olesen J, Physiotherapy for tension-type headache: a controlled study, Cephalalgia, 2004;24:29-36.

84. van Ettekoven $\mathrm{H}$, Lucas C, Efficacy of physiotherapy including a craniocervical training programme for tension-type headache; a randomized clinical trial, Cephalalgia, 2006;26:983-91.

85. Biondi DM, Physical treatments for headache: a structured review, Headache, 2005;45:738-46.

86. Lenssinck ML, Damen L, Verhagen AP, et al., The effectiveness of physiotherapy and manipulation in patients with tension-type headache: a systematic review, Pain, 2004;112:381-8

87. Davis MA, Kononowech RW, Rolin SA, Spierings EL, Acupuncture for tension-type headache: a meta-analysis of randomized, controlled trials, J Pain, 2008:9:667-77.

88. Jena $\mathrm{S}$, Witt $\mathrm{CM}$, Brinkhaus $\mathrm{B}$, et al., Acupuncture in patients with headache, Cephalalgia, 2008:28:969-79.

89. Melchart D, Streng A, Hoppe A, et al., Acupuncture in patients with tension-type headache: randomised controlled trial, Br Med J, 2005;331:376-82.

90. Tavola T, Gala C, Conte G, Invernizzi G, Traditional Chinese acupuncture in tension-type headache: a controlled study, Pain, 1992;48:325-9.

91. Endres $\mathrm{HG}$, Bowing $\mathrm{G}$, Diener $\mathrm{HC}$, et al., Acupuncture for tension-type headache: a multicentre, sham-controlled, patient-and observer-blinded, randomised trial, I Headache patient-and observer-bin

92. Karst M, Reinhard M, Thum P, et al., Needle acupuncture in tension-type headache: a randomized, placebo-controlled study, Cephalalgia, 2001;21:637-42.

93. White AR, Resch KL, Chan JC, et al., Acupuncture for episodic tension-type headache: a multicentre randomized controlled trial, Cephalalgia, 2000;20:632-7.

94. Soderberg E, Carlsson J, Stener-Victorin E, Chronic tension-type headache treated with acupuncture, physical training and relaxation training. Between-group differences, Cephalalgia, 2006;26:1320-9.

95. Ahonen $\mathrm{E}$, Hakumaki M, Mahlamaki S, et al., Effectiveness of acupuncture and physiotherapy on myogenic headache: a comparative study, Acupunct Electrother Res, 1984;9:141-50.

96. Wylie KR, Jackson C, Crawford PM, Does psychological testing help to predict the response to acupuncture or massage/relaxation therapy in patients presenting to a general neurology clinic with headache?, I Tradit chin Med, 1997;17:130-9. 